\title{
RISK INDICATORS FOR ROAD ACCIDENT IN POLAND FOR THE PERIOD 2004-2017
}

\author{
Witold Pawłowski ${ }^{1}$, Krzysztof Goniewicz ${ }^{2}$, Katarzyna Naylor ${ }^{3}$, Mariusz Goniewicz $^{4}$, Dorota Lasota ${ }^{5}$ \\ 1Department of Disaster Medicine, Medical University of Warsaw, Warsaw, Poland \\ ${ }^{2}$ Department of Security Studies, Polish Air Force Academy, Deblin, Poland \\ ${ }^{3}$ Department of Didactics and Medical Simulation, Medical University of Lublin, Lublin, Poland \\ ${ }^{4}$ Department of Emergency Medicine, Medical University of Lublin, Lublin, Poland \\ ${ }^{5}$ Department of Experimental and Clinical Pharmacology, Medical University of Warsaw, Warsaw, Poland
}

\begin{abstract}
SUMMARY
Objective: The aim of the research was to assess the prevalence, effects and risk factors for motor vehicle accidents (MVA) in the years 2004-2017 in Poland.

Method: We merged secondary data from the Prevention and Analysis Office of Road Traffic Headquarters of Police and Central Statistical Office of Poland.

Results: Our results suggest that several thousand people are killed on Polish roads annually, and tens of thousands are injured. Road crashes represent the leading cause of death for Polish men up to 44 years of age. The most common causes of road crashes in Poland include failure to comply with the road traffic rules and low driving skills. We also found drivers who poorly assessed road situations, roads characterized by a lack of adequate road infrastructure, and many vehicles in poor condition. Road crashes have become a significant public health and social problem globally. Drivers caused most MVA in Poland in the years 2004-2017, whereas the underlying cause was inadequate speed regarding the road traffic condition as well as not respecting the right-of-way. Despite various measures that are being taken to improve safety on Polish roads, the number of the dead and wounded as a result of road accidents is still high and the losses to the society are considerable as well.

Conclusion: It is necessary to continue multidirectional actions to improve safety on the roads in Poland resulting in a systematic increase in the level of road traffic security.
\end{abstract}

Key words: road traffic accidents, mortality rates, injury rates, vehicle speeding, traffic violations

Address for correspondence: W. Pawłowski, Department of Disaster Medicine, Medical University of Warsaw, Zwirki i Wigury 81 street, $02-091$ Warsaw, Poland. E-mail: witold.pawlowski@wum.edu.pl

https://doi.org/10.21101/cejph.a4791

\section{INTRODUCTION}

The outcomes of road traffic accidents have become a significant public health and social problem globally. The World Health Organization (WHO) alarms that annually 1.3 million road fatalities occur worldwide, whereas 20 to 50 million people are casualties with traumas demanding long-term and costly care. Moreover, lack of efforts aimed at improving road safety will result in an increased number of fatalities and casualties as outcomes of motor vehicle accidents (MVA) by about $65 \%$ over the next 20 years. Additionally, the WHO projections place MVA as the fifth leading cause of death by the year 2030, resulting in $3.6 \%$ of all deaths globally (1).

In Poland, every fourth death being a result of external reasons occur because of MVA; the total being triple the rate of mortality in Western European countries (1). The Polish officials have implemented some methods directed at increasing road safety in Poland. Those improvements evolve around educating road users, penalizing for breaking traffic law, novel regulations of technical condition of automobiles, and modernising the roads. Nevertheless, the number of deaths and injuries being a result of MVA is still substantial.
The aim of this study was to analyse patterns in recorded fatalities from MVA over the period from 2004 to 2017, as well as factors connected to the environment that may lead to crashes.

\section{MATERIALS AND METHODS}

We reviewed and combined secondary data from the Prevention and Analysis Office of Road Traffic Headquarters of Police and Central Statistical Office of Poland. When analysing the data, the visible patterns were selected for further analyses.

\section{RESULTS}

2010 was the final year of employing the European road safety programme. Thus, it was the first year when the incidence of MVA resulting in deaths decreased below 4,000 (Fig. 1). Moreover, there was a downward trend in both the number of MVA and the injured, third year in a row. When analysing the period 2004-2017, 574,982 road accidents were recorded on Polish roads. Those 
MVA resulted in 61,012 fatalities and 717,201 casualties (3). In Poland, the threat of fatal road crashes is still high compared to other European countries. It is almost three times higher than in Holland and 2.5 higher than in Sweden and Great Britain. In Poland, in the years 2001-2010, the number of road fatalities decreased by $29 \%$ and the number of crashes and injuries decreased by $28 \%$. It was one of the smallest declines among the Member States of the European Union (4).

Polish society is not aware of the real economic and social losses incurred due to crashes on the roads (4). However, World Bank experts estimate that the annual cost of fatal crashes in Poland is nearly 2.6 billion Euro and the cost of all the consequences of motor vehicle crashes is between 6.3 to 8 billion Euro. This amount equals to about $2 \%$ of Polish GDP (5).

\section{Time of Road Crashes}

In the years 2004-2017 the most road accidents occurred in October, July and August. According to the Police Headquarters, a large number of accidents in the summer and autumn months are connected with the increased traffic during holiday time and the deterioration of weather and road conditions in autumn $(2,3)$. In these months the biggest number of fatalities and casualties resulting from road accidents was reported. The least number of accidents was reported in January and February. In these months was also reported the least number of fatalities and injuries. A substantial reduction in the number of accidents and victims of road accidents in January and February is primarily connected with difficult road conditions (ice and snow) and cautious behaviour of drivers $(2,3)$.

Analysing the incidence of road accidents depending on the day of the week, it was found that their intensity increased at the end of the week, especially on Fridays. However, most people died on Saturday (Fig. 2). Alcohol impairment probably constitutes an important factor.

The majority of road accidents in Poland in the years 20042017 took place in good weather conditions, in daylight and the roads being dry. Favourable weather conditions cause a reduction of concentration and make the drivers fail to keep due care while manoeuvring, and above all, encourage them to exceed the speed limit (6). As the data analysis shows, driving at excessive speed in case of an accident leads to tragic consequences. In such circumstances, more people die or get severely injured, e.g. in $2013,8,276$ accidents occurred due to the fact that drivers

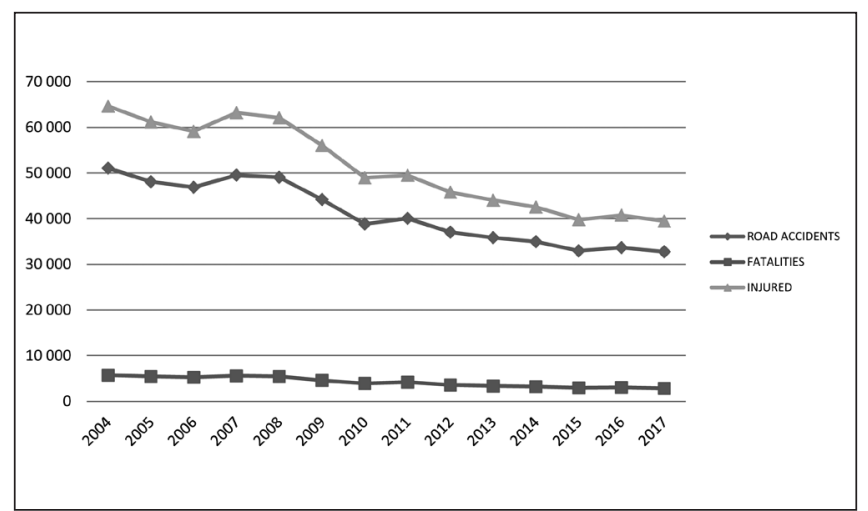

Fig. 1. Road accidents, fatalities, injured in Poland. Source: Polish Police Headquarter, CSO

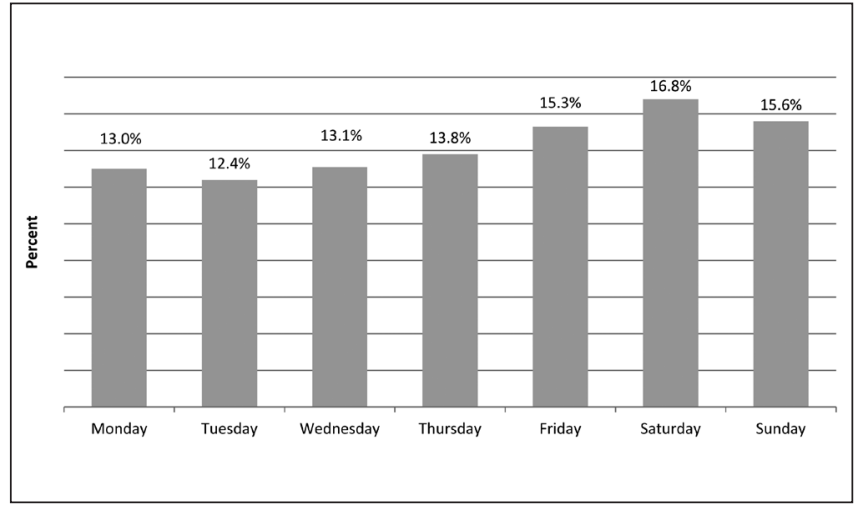

Fig. 2. Road accidents in Poland by day of the week.

failed to adjust the speed to road conditions (28.2\%), 966 people were killed (42.6\%), 11,344 were injured (30.2\%). Lighting has a similar effect on the occurrence of road accidents $(2,3)$. In the period in question most accidents occurred during the day (almost $70 \%$ ), but in 2014 , for example, the majority of people were killed during the night. One quarter of casualties were killed during the night and one thirteenth during the day $(2,3)$.

In the years 2004-2017 most accidents happened on dry roads (64\%); $28 \%$ were accidents on wet roads. Up to $7 \%$ of the events occurred on icy or snowy road, while $1 \%$ of accidents occurred on roads polluted with mud, oil or leaves $(2,3)$. Research conducted at the Institute of Road Transport has shown that at the speed of 50 $\mathrm{km} / \mathrm{h}$ vehicle distance on dry roads is, depending on the power of braking, from 28 to 33 meters, however, at the speed of $60 \mathrm{~km} / \mathrm{h}$ the distance increases from 36.5 to 44.5 meters. On wet roads, braking distances are even longer $(2,3)$. When the road surface is covered with a dense layer of snow, traction with the road greatly decreases and almost disappears in case of black ice. The implemented tests show that the road covered with snow makes the braking distance twice as long, whereas icy roads make the distance four times longer (7).

\section{Sites of Road Accidents}

Analysis of data on the area of road accidents occurrence shows that although the majority of them occurred in urban areas $(56 \%$ accidents) more people died in accidents occurring in a nonbuilt-up area (44\% accidents) (Table 1). According to the Police Headquarters, drivers in a non-built-up area have the tendency to greatly exceed the speed limit and it takes longer to reach the injured by emergency services what results in more fatalities (3).

In the years 2004-2017 the most accidents (almost 60\%) were reported on straight roads. As a result, the largest number of people were killed or injured. Other particularly dangerous places according to the geometry of the road were the intersections and right of ways (almost $20 \%$ of accidents), as well as sharp curves and bends of the roads (about $10 \%$ of accidents) $(2,3)$.

The road accidents in the years 2004-2017 took place on the roadway (almost $80 \%$ of accidents), pedestrian crossing (almost $9 \%$ of accidents), and roadside (about $4 \%$ of accidents). The remaining accidents happened in the following places: escarpment, ditch, pavement, pedestrian road, driveway, car park, square, public transport stop, tram crossing, cycle path, railway crossing, bridge, viaduct, overpass, and tunnel $(2,3)$. 
Table 1. Road accidents and their consequences in Poland by area of occurrence, 2004-2017

\begin{tabular}{|c|c|c|c|c|}
\hline Year & Area & Road accidents & Fatalities & Injuries \\
\hline \multirow{2}{*}{2004} & Urban & 36,694 & 2,755 & 44,372 \\
\hline & Non built-up & 14,375 & 2,957 & 20,289 \\
\hline \multirow{2}{*}{2005} & Urban & 34,273 & 2,495 & 41,393 \\
\hline & Non built-up & 13,827 & 2,949 & 19,797 \\
\hline \multirow{2}{*}{2006} & Urban & 33,531 & 2,349 & 40,506 \\
\hline & Non built-up & 13,345 & 2,894 & 18,617 \\
\hline \multirow{2}{*}{2007} & Urban & 35,200 & 2,549 & 42,768 \\
\hline & Non built-up & 14,336 & 3,304 & 20,456 \\
\hline \multirow{2}{*}{2008} & Urban & 34,881 & 2,499 & 42,012 \\
\hline & Non built-up & 14,173 & 2,938 & 20,085 \\
\hline \multirow{2}{*}{2009} & Urban & 31,599 & 2,171 & 38,277 \\
\hline & Non built-up & 12,597 & 2,401 & 17,769 \\
\hline \multirow{2}{*}{2010} & Urban & 27,836 & 1,812 & 33,364 \\
\hline & Non built-up & 10,996 & 2,095 & 15,588 \\
\hline \multirow{2}{*}{2011} & Urban & 29,174 & 1,961 & 34,856 \\
\hline & Non built-up & 10,891 & 2,228 & 14,645 \\
\hline \multirow{2}{*}{2012} & Urban & 27,056 & 1,652 & 32,071 \\
\hline & Non built-up & 9,990 & 1,919 & 13,721 \\
\hline \multirow{2}{*}{2013} & Urban & 26,078 & 1,581 & 30,935 \\
\hline & Non built-up & 9,769 & 1,776 & 13,124 \\
\hline \multirow{2}{*}{2014} & Urban & 25,368 & 1,466 & 29,767 \\
\hline & Non built-up & 9,602 & 1,736 & 12,778 \\
\hline \multirow{2}{*}{2015} & Urban & 23,658 & 1,248 & 27,431 \\
\hline & Non built-up & 9,309 & 1,690 & 12,347 \\
\hline \multirow{2}{*}{2016} & Urban & 23,896 & 1,275 & 27,696 \\
\hline & Non built-up & 9,795 & 1,751 & 13,070 \\
\hline \multirow{2}{*}{2017} & Urban & 23,262 & 1,238 & 27,014 \\
\hline & Non built-up & 9,498 & 1,593 & 12,452 \\
\hline
\end{tabular}

In the years 2004-2017 the vast majority of accidents occurred on single carriageway two-way roads. These events accounted for over $81 \%$ of all accidents. Additionally, high number of fatalities (almost $88 \%$ of all killed in road accidents) and high number of injured ( $82 \%$ of all casualties in road accidents) characterized those events. The concentration of the majority of accidents on single carriageway roads straight, bi-directional and linking it with the most common causes of accidents caused by drivers, namely inappropriate speed for the road conditions as well as incorrect manoeuvres, shows inadequacy of road infrastructure in Poland to the increasing volume of traffic $(2,3)$. Road networks in Poland have many deficiencies, which clearly contribute to drivers' incorrect decisions.

\section{Intoxicated Road Users}

In the years 2004-2017, an intoxicated driver caused almost every fifth road crash in Poland. Considering the number of intoxicated offenders in relation to the category of road users, a decrease in the number of events caused by drunken pedes- trians has been observed, and an increase has been observed in the category of drivers. During the period in question, the largest group of intoxicated perpetrators of crashes were vehicle drivers. In the group, intoxicated drivers caused the majority of crashes (more than $80 \%$ of the crashes) caused by intoxicated drivers (8). The events caused by intoxicated drivers were the most severe crashes, and they resulted in numerous fatalities. Drunken road users caused about $10 \%$ of crashes, of which more than $12 \%$ were fatal. According to the analysed statistics the number of people intoxicated at night - drivers, pedestrians, and cyclists - rose to $50 \%$. During the day, the percentage of intoxicated drivers involved in road traffic crashes accounted for over $10 \%(2,3,8,9)$. Average concentrations of alcohol found in the blood of pedestrians killed in crashes were excessive, reaching as high as $2.4 \%$ of alcohol. The degree of intoxication and the number of intoxicated people increased noticeably on public holidays. The most crashes were caused by drunk drivers since they failed to adjust the speed to traffic conditions or they either failed to obey the right of way or drove on the wrong side of the road. 


\section{Comparisons of Trends in 2004 and 2017}

Motor vehicle crashes in Poland have decreased between 2004 and 2017. In fact, the total number of MVA dropped by more than 15,000 and the number of fatalities decreased nearly by half over the 10-year period. The reasons behind the drop are probably connected to technical improvements of the roads. Additionally, traffic laws were implemented to punish reckless drivers (10).

The trend of a constant decline between 2004 and 2012 is noticeably evident when analysing two particular months: August and October. Both months have drops of over 2,000 crashes between 2004 and 2012, the highest drops of any months. They also show fewer people killed and injured.

The positive change is also noticed when analysing the numbers of road crashes in particular days of the week. However, it is not as distinct as in other categories: a drop by around 1,000 crashes on each day between 2004 and 2017.

\section{CONCLUSIONS}

Traffic crashes claim more deaths than war, and millions of people are handicapped because of road accidents (11). Social and economic impacts of such a large number of road crashes and their consequences leading to death or disability are severe. Additionally, the costs of road crashes have a significant impact on the economy of many countries, particularly low- and middleincome countries, which are often struggling with other development needs. In Poland, the costs of road traffic crashes absorb $2.1 \%$ of gross domestic product (12).

Poland's progress between 2004-2017 is mixed. There was a clear decline in the number of crashes, injuries and mortality rates over the decade; a promising sign. However, driving on Polish roads continues to represent risk that is higher than in most other European countries (13). There are several possible reasons for this. The level of road safety places Poland as one of the riskiest nations to drive among European countries. Drivers caused the majority of road crashes in Poland. The main causes of crashes were speed inappropriate for road conditions and failure to give way. In the years 2004-2017 the vast majority of crashes resulted in pedestrian casualties/fatalities and/or were a result of intoxicated road user. To improve security on the roads in Poland it is necessary to continue numerous measures aimed at improving the road safety systematically and persistently. Road users need to abide by the traffic rules. Institutions responsible for traffic need to ensure safe road infrastructure and manufacturers need to produce safer vehicles.

\section{Acknowledgement}

The authors would like to thank the Efficient English School in Lublin for an outstanding job of editorial translation.

\section{Conflict of Interests}

None declared

\section{REFERENCES}

1. World Health Organization. Global status report on road safety 2015. Geneva: WHO; 2015.

2. Central Statistical Office of Poland [Internet]. [cited 2018 Aug 19]. Available from: http://www.stat.gov.pl.

3. Prevention and Analysis Office of the Road Traffic Headquarters of Police [Internet]. [cited 2018 Aug 20]. Available from: http://www.policja.pl. (In Polish.)

4. Olszewski P, Szagala P, Wolanski M, Zielinska A. Pedestrian fatality risk in accidents at unsignalized zebra crosswalks in Poland. Accid Anal Prev. 2015;84:83-91.

5. Country report on Poland: road safety management capacity review. Report no. 78319-PL. Washington DC: World Bank; 2013.

6. Macioszek E. The road safety at turbo roundabouts in Poland. Arch Transp. 2015;33(1):57-67.

7. Radziszewski P, Nazarko J, Vilutiene T, Debkowska K, Ejdys J, Gudanowska A, et al. Future trends in road pavement technologies development in the context of environmental protection. Baltic J Road Bridge Eng. 2016;11(2):160-8.

8. Lasota D, Staniszewska A, Tarchalska-Krynska B, Mirowska-Guzel D, Krajewski P. Insobriety and the risk of death in traffic accident. J Educ Health Sport. 2015;5(6):419-32.

9. Adamowicz P, Gieroń J, Gil D, Lechowicz W, Skulska A, Tokarczyk B. The prevalence of new psychoactive substances in biological material - a three-year review of casework in Poland. Drug Test Anal. 2016;8(1):6370.

10. Paradowska M. Comparison of road safety policy objectives in Poland and in the European Union. In: Bąk M, editor. Transport development challenges in the twenty-first century: Proceedings of the 2015 TranSopot Conference. Wien: Springer; 2016. p. 103-23.

11. Artamoshina MP. The European countries' government programs targeted to decrease the road traffic injuries. Probl Sotsialnoi Gig Zdravookhranenniiai Istor Med. 2008 Nov-Dec;(6):39-44. (In Russian.)

12. Bergel-Hayat R, Zukowska J. Road safety trends at national level in Europe: a review of time-series analysis performed during the period 2000-12. Transp Rev. 2015;35(5):650-71.

13. Goniewicz K, Goniewicz M, Pawłowski W, Fiedor P. Road accident rates: strategies and programmes for improving road traffic safety. Eur J Trauma Emerg Surg. 2016 Aug;42(4):433-8.

Received April 6, 2016 Accepted in revised form August 1, 2018 